\section{TRANSIDENTIDADES PARA UMA EDUCAÇÃO FÍSICA ACOLHEDORA}

\author{
TRANSIDENTITIES FOR A WELCOMING PHYSICAL EDUCATION C己 \\ TRANSIDENTIDADES PARA UNA EDUCACIÓN FÍSICA ACOGEDORA C己
}

d6) https://doi.org/10.22456/1982-8918.116297

(D) Carlos Henrique Rego Gonçalves* <carlossiga@yahoo.com.br>

(D) Carlos Alberto Figueiredo da Silva* <ca.figueiredo@yahoo.com.br>

*Universidade Salgado de Oliveira. Niterói, RJ, Brasil.

Resumo: O objetivo deste estudo é discutir o processo de exclusão resultante de projetos curriculares pautados em identidades minoritárias prontas, de forma a questionar as representações sociais majoritárias naturalizadas na Educação Física. Utilizou-se a técnica de revisão bibliográfica do tipo qualitativa, constituindo-se como uma revisão narrativa. Foi consultado o banco de dados do Google Acadêmico, no período entre 2000 e 2021, utilizando-se indicador booleano e descritores entre aspas. Justifica-se este estudo em função de que vários caminhos didático-pedagógicos presentes na literatura desconsideram diversas subjetividades, experiências e diferenças existentes dentro das diferenças, negligenciando a construção de identidades formadas dentro dos próprios marcadores identitários. Conclui-se que, ao se incentivar a coalizão entre várias teorias pós-críticas, assegura-se o sabor de novidade e a verve revolucionária fundamental para resolução de problemas identitários e projetos curriculares que buscam suplantar qualquer tipo de ficção naturalizante.

Palavras chave: Educação Física. Interseccionalidade. Minorias sexuais e de gênero. Construção social do gênero.
Recebido em: 29 jun. 2021 Aprovado em: 21 nov. 2021 Publicado em: 30 dez. 2021

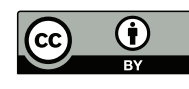

Este é um artigo publicado sob a licença Creative Commons Atribuição 4.0 Internacional (CC BY 4.0). eISSN: 1982-8918 


\section{INTRODUÇÃO}

A Constituição do Brasil de 1988 define a educação como um direito de todos e dever do Estado, estabelecendo como um dos princípios: a igualdade de condições para acesso e permanência na escola (BRASIL, 2016). Porém, em análise dos resultados da pesquisa anual por amostra de domicílios contínua (PNAD-Contínua), módulo Educação, realizada em 2019, é possível identificar que o país vem ao longo dos últimos anos aumentando o percentual de jovens entre 15 e 17 anos matriculados no ensino médio: 67,6\% em 2017, 68,7\% em 2018, 71,1\% em 2019. Mas os problemas de evasão e abandono permanecem, principalmente entre jovens que fazem parte de grupos minoritários, tais como pobres e negros (IBGE, 2019).

Cada grupo de jovens tem suas próprias alegações para não seguir estudando ou ampliando a sua qualificação e, por isso, acabam sendo subjugados e marginalizados. Ocorre que, com a nova redação dada ao artigo $4^{\circ}$ da LDB 9394/96, pela Lei no 12.796/2013, toda Educação Básica passou a ser obrigatória dos quatro aos 17 anos, devendo toda criança e adolescente, nessa faixa etária, estar matriculado e frequentando a escola (BRASIL, 1996).

Embora a Educação Física continue sendo vista, por uma pequena parcela de professores, diretores e pedagogos, como de menor importância pedagógica (VASCONCELOS; CAMPOS, 2014), esse caráter provocativo e algumas vezes até mal-intencionado aparece por identificar na Educação Física algum tipo de saída e/ ou resistência com relação aos principais problemas que assolam o ensino médio, que são: o desinteresse, o afastamento e a evasão escolar (IBGE, 2019). O que esse pequeno grupo de profissionais não reparou é que a baixa participação de adolescentes nas aulas de Educação Física é uma realidade comprovada (ARAÚJO et al., 2019).

Apesar dos motivos da baixa participação dos estudantes do ensino médio na Educação Física serem inconsistentes (ARAÚJO et al., 2019), o desejo de construir uma nova Educação Física Escolar, que possibilite aos estudantes a aprendizagem de conhecimentos significantes, tem provocado mudanças na prática pedagógica dos seus professores (MALDONADO et al., 2018).

Oliveira Junior (2017) e Neves (2018) evidenciaram que a prática inspirada no currículo cultural de Educação Física está alinhada com as políticas em prol de grupos marginalizados, oprimidos e subjugados. Entretanto, os sujeitos pedagógicos produzidos pelo currículo cultural agem de acordo com seus próprios regimes de verdade, pautados em princípios democráticos (BORGES, 2019). Estaria tal raciocínio revelando uma nova lógica pedagógica sistematizada pelo olhar universal do mundo dos oprimidos para Educação Física? Ou revelando um movimento dinâmico que traz, para o campo pedagógico da Educação Física, vozes dissonantes, inquietações, expectativas e resistências de identidades e grupos que precisam ser visibilizados?

Essa inquietação foi desencadeada durante reuniões pedagógicas semanais, ocorridas em uma unidade escolar federal, com docentes de Educação Física que atuavam especificamente com o ensino médio. A pauta da reunião valorizava a troca de experiência entre os docentes, que ponderavam sobre as práticas pedagógicas 
materializadas e possíveis encaminhamentos pedagógicos futuros. Era perceptível, no discurso da maioria dos docentes, certo engessamento, principalmente no tocante à definição de determinadas identidades como prioridade.

Como sinaliza Gallo (2015), muitos docentes partem do trabalho de identidades minoritárias prontas, uma diferença rastreável, identificável, impedindo maiores criações - uma moralização das diferenças. Esse tipo de condução didática pode ter efeitos deletérios no processo de ensino e aprendizagem da Educação Física. Ao desconsiderar as diversas subjetividades, experiências e diferenças existentes dentro das diferenças, negligencia-se a construção de identidades diferentes, inclusive, formadas dentro dos próprios marcadores identitários; além de não refletir as relações de poder travadas no interior desses marcadores identitários, que contribuem com o avanço do processo de exclusão da exclusão, cada vez mais comum no âmbito escolar e social.

Mesmo optando pela adesão/construção de um currículo cultural de Educação Física, o docente não está imune de realizar uma política identitária, principalmente quando se concentra em afirmar identidades culturais marginalizadas. Segundo Vieira (2020), o docente, ao homogeneizar indivíduos a partir das suas culturas, congeladas no tempo e espaço e entendidas com frequência como algo que apresenta certa pureza, corre o risco de promover uma síntese identitária que circunscreve a diferença enquanto possibilidade rastreável, em que as tematizações giram muitas vezes em torno de marcadores identitários como gênero, raça, etnia, sexualidade e religião.

Esse tipo de homogeneização, criticada há várias décadas como modo de expressão da diferença (MISKOLCI, 2021), classifica e padroniza as identidades em marcas sociais de diferenças, apaga a diversidade e os atravessamentos presentes nos jovens e impossibilita compreendê-los enquanto indivíduos que têm "uma historicidade, com visões de mundo, escalas de valores, sentimentos, emoções, desejos, projetos, com lógicas de comportamentos e hábitos que the são próprios" (DAYRELL, 1996, p.140).

O caminho escolhido para buscar possíveis respostas para essas armadilhas didático-pedagógicas parte de uma "instabilidade conceitual" no uso da "identidade" como categoria de análise. Para esse fim, usamos neste estudo o termo "TRANSidentidade" como um significante vazio (LACLAU, 1996, p. 68), capaz de expandir o potencial de contestação identitária; problematizar identidades consideradas naturais, normais e estabelecidas; materializar a ideia de que somos "livres para fazer e desfazer identidades à vontade" (BAUMAN, 2001, p. 98); que "existimos porque somos diferentes, porque consistimos em diferença" (BAUMAN, 2009 b, p. 76); que somos seres humanos em constante transformação e fluidez (BAUMAN, 2001).

O termo "TRANSidentidade" se diferencia e avança em relação aos estudos concentrados nas temáticas de gênero e sexualidade na Educação Física (ALTMANN, 2015; DEVIDE, 2017; DORNELLES; WENETZ; SCHWENGBER, 2014, 2017). Procuramos, com este texto, aduzir que a todo momento surgem novas subjetividades diferentes, novas identidades diferentes e novos sujeitos políticos 
diferentes que precisam, assim como as mulheres e o público LGBTQIA+, resistir às etiquetas normativas, preconceitos e discriminações sociais e na Educação Física.

Embora o currículo cultural de Educação Física venha contribuindo para uma educação valorizadora da diversidade de identidades, não basta constatar! É preciso analisar criticamente os discursos que fabricam essas identidades e essas diferenças, buscando interpretar a identidade como construção, ela própria múltipla e plural (CANEN, 2020).

Apresentepesquisa, influenciadapelosestudosqueerepelainterseccionalidade, busca tornar mais criterioso o olhar docente sobre a natureza interseccional e política das próprias identidades (COHEN, 1997), reconhecendo que não faz sentido supor que identidades entre sujeitos classificados em categorias idênticas sejam iguais (MCDONALD, 2013). Um exemplo emblemático dessa situação pode ser visualizado a partir do critério do colorismo e da pigmentocracia. No Brasil, quanto mais escura for a sua pele, mais será discriminado. Isso não quer dizer que pretos mais claros não sofram com o racismo, mas terão mais passabilidade. Como aponta Crenshaw (1991), as políticas identitárias não negligenciam o reconhecimento das diferenças, mas, antes, desconsideram ou desmerecem as diferenças existentes dentro do próprio grupo.

Dessarte, nosso esforço reflexivo questiona as representações sociais majoritárias naturalizadas na Educação Física Escolar, sem se descuidar, contudo, de refletir as subjetividades discentes em suas dimensões individuais e coletivas (CANEN; CANEN, 2005). Dessa forma, observamos perspectivas, principalmente aquelas inspiradas pelo currículo cultural, que escolhem e priorizam pobres, negros, índios, deficientes, homossexuais e mulheres nas práticas pedagógicas da Educação Física, sem considerar as singularidades, hibridações e atravessamentos presentes nessas identidades, pois entendemos que elas impossibilitam que outras formas de exclusão, provenientes desses marcadores, também sejam problematizadas.

Não postulamos criar um novo conceito de identidade, já que entendemos identidade como algo construído nas interações humanas e a todo o momento; nem mesmo abolir o conceito de identidade e suas lutas representativas de grupos vulneráveis. Nossa ressalva está na reificação do termo identidade, sobre a formação de identidades coisificadas e/ou putativas que cristalizam as pessoas em uma única via de compreensão, quase sempre tirânica.

Estamos cônscios de que o uso prático do termo "TRANSidentidade", no cotidiano da Educação Física Escolar, evita o erro de congelar e homogeneizar identidades e diferenças (CANEN, 2020) e permite que as "diferenças dentro das diferenças" sejam constantemente percebidas e analisadas (SOUZA SANTOS, 2001). O docente de Educação Física, ciente de que as identidades discentes são transitórias, relacionais, múltiplas, descentradas, fragmentadas, fluidas, deslocadas, performáticas, liquefeitas e que estão em constante construção, desconstrução e/ ou reconstrução (BAUMAN, 2009a, 2001; BRAH, 2006; BUTLER, 2010; COLLING, 2013; KNUDSEN, 2006), se apropria do termo "TRANSidentidade" como um termo crítico, desconstruindo qualquer sentido pejorativo pelo esclarecimento da identidade como um território em constante transformação para TODOS os sujeitos sociais. 
Embora exista um arcabouço sólido de produção científica acerca do processo de inclusão/exclusão na Educação Física Escolar, esta pesquisa parte de algumas lacunas encontradas na literatura, tais como: 1) a limitada quantidade de estudos que se propuseram a entender o processo de exclusão e autoexclusão em ambientes escolares com fatores que facilitam a prática pedagógica (espaço físico e material adequado e qualidade do corpo docente); 2) ausência de estudos que se propõem a investigar identidades diferentes formadas dentro das diferenças em espaços que desenvolvem um currículo cultural de Educação Física; 3) ausência de estudos que analisam a contribuição que a interseccionalidade pode agregar ao currículo cultural de Educação Física; 4) ausência de estudos na área de Educação Física que refletem a relação "identidade versus trans" para além do seu caráter sexual ou de gênero.

A Educação Física, por se deparar diuturnamente com situações desiguais, preconceitos e sectarismos (OLIVEIRA; DAOLIO, 2010), precisa continuar aberta e atenta aos fluxos constantes que transformam grupos (TRANSidentidade social), pessoas (TRANSidentidades dos atores sociais) e espaços (TRANSidentidade da escola e Educação Física), para que, assim, possa acolher e incluir os sujeitos sociais/discentes de forma democrática e equitativa.

O objetivo deste estudo é discutir o processo de exclusão resultante de projetos curriculares pautados em identidades minoritárias prontas, de forma a questionar as representações sociais majoritárias naturalizadas na Educação Física.

Dessa forma, busca-se refletir sobre as subjetividades discentes em suas dimensões: individuais (percebendo as singularidades, hibridações e atravessamentos) e coletivas (reconhecendo de forma temporária algum ou alguns marcadores que conferem sentimento de pertença a grupos coletivos específicos).

\section{METODOLOGIA}

O presente estudo, de caráter teórico, foi realizado através da técnica de revisão bibliográfica do tipo qualitativa, constituindo-se como uma revisão narrativa (ELIAS et al., 2012). Tradicionalmente, esta modalidade de pesquisa vai em busca de respostas para um determinado problema através de referenciais teóricos já publicados em forma de livros, artigos, teses, dissertações (CERVO; BERVIAN; SILVA, 2007).

De acordo com Oliveira (1997), o objetivo é explorar as diversas formas de contribuição científica dos múltiplos assuntos e fenômenos que já foram estudados. Este trabalho pode ser considerado como pesquisa exploratória, pois o "objetivo é familiarizar-se com o fenômeno ou obter uma nova percepção dele e descobrir novas ideias" (CERVO; BERVIAN; SILVA, 2007).

Para a busca por materiais, realizou-se uma pesquisa no banco de dados do Google Acadêmico, no período entre 2000 e 2021, utilizando o indicador booleano AND e os descritores entre aspas "currículo cultural de educação física" AND "identidade" AND "teoria queer" AND "interseccionalidade".

Inicialmente não encontramos fontes que englobassem todos os descritores. Sendo assim, optamos por desmembrar os descritores em grupos, um par e dois 
trios, para proceder à pesquisa. Com o primeiro par de descritores, "currículo cultural de educação física" AND "identidade", encontramos 66 resultados; com o primeiro trio, "currículo cultural de educação física" AND "teoria queer" AND "identidade", encontramos aproximadamente 13 resultados; finalmente, com o segundo trio, "currículo cultural de educação física" AND "interseccionalidade" AND "identidade", encontramos apenas um único resultado. Após a leitura de todos os títulos e análise dos resumos, foram selecionados 30 artigos e quatro teses para apreciação na íntegra.

\section{CURRÍCULO: DOCUMENTO DE TRANSIDENTIDADE}

Para lidar atualmente com o tema identidade é preciso ter clara a noção de que somos diferentes; e que respeitar as diferenças ainda é uma dificuldade para a sociedade brasileira de consumo (capitalista) e, consequentemente, um desafio a ser superado pelas escolas. Essa realidade adversa materializada através do currículo, que muitas vezes, de forma naturalizada e acrítica, acaba privilegiando culturas, conhecimentos e determinados tipos de identidades sociais em detrimento de outras, passou a ser questionada e tornou-se objeto de estudo de muitos pesquisadores, (CANDAU, 2008, 2013; CANEN, 2012, 2020; CANEN; GRANT, 2001; NEIRA, 2009; 2020; NUNES; RUBIO, 2008), que lutam diariamente por uma educação democrática que inclua seres plurais. Seja por força de lei, pressões econômicas e/ou conquistas sociais de grupos desprovidos de poder, uma série de adaptações curriculares estão sendo pensadas e implantadas (GALVE; TRALLERO; HEREDERO 2002).

É assim que, segundo Silva (2007), o currículo pós-crítico nasce e assume a responsabilidade pela valorização do direito às diferenças; pelo reconhecimento da existência de múltiplas identidades; pela desconstrução de dogmas solidificados histórica, cultural e socialmente; e, principalmente, por refletir as relações de poder existentes entre identidades (FOUCAULT, 2012).

Essa condição desencadeou na Educação Física um movimento fundamental de ruptura do processo de exclusão e silenciamentos de culturas e identidades inferiorizadas: na inclusão de uma multiplicidade de vozes anteriormente preteridas; na descoberta de novas dimensões de muitas experiências; no combate a discursos preconceituosos e homogeneizantes; na divulgação de novas formas de ver a cultura e a Educação Física dominante. Mesmo com todos esses avanços repercutindo de forma pedagogicamente positiva na Educação Física, proporcionando aos discentes a compreensão dos motivos da sua condição subalternizada (NEIRA, 2009) e clareza sobre a natureza do preconceito e visão ampla das relações sociais (KINCHELOE; STEINBERG, 1999), ainda vemos como de extrema urgência a necessidade de elucidar os docentes sobre a importância de interpretar a identidade como uma questão de produção que deve ser constantemente problematizada.

Borges (2019) identificou que os campos teóricos mais presentes nos discursos e práticas dos professores que assumem colocar a proposta curricular pós-crítica de Educação Física em ação são: o multiculturalismo crítico e os estudos culturais. Tal influência, fortemente representada por uma ação mais contundente sobre as 
relações de poder travadas entre os diferentes grupos sociais e culturais (pobre, negro, índio, mulher, cristão, deficiente, homossexual etc.), tem implicação direta na opção e defesa pela constituição de 'identidades solidárias' (NEIRA; SANTOS, 2019; NEVES, 2018). Mas como evitar que a formação de 'identidades solidárias' compactue com uma visão reducionista de identidade universal, estática, estável e binária? Como evitar que esses marcadores identitários se tornem 'marcadores mestres' (CANEN; GRANT, 2001) e impeçam que outras subjetividades e experiências possam surgir? Como evitar que os marcadores identitários sejam computados como aditivos de opressão? Como evitar que os marcadores identitários sejam percebidos de forma estanque e ocultem a natureza interseccional que atravessa as identidades? Como evitar que sujeitos classificados em categorias identitárias idênticas sejam considerados iguais?

Se, por um lado, o currículo pós-crítico e a Educação Física cultural viabilizam em grande escala o entendimento da heterogeneidade social mediante a democratização de políticas de identidade (TORRES-SANTOMÉ, 1998), por outro, pouco oportunizam "a compreensão das conexões e hibridizações inerentes ao processo de construção das identidades" (CANEN, 2012). Partindo deste prisma, usamos o termo "TRANSidentidade" como estratégia capaz de manter o docente sempre alerta sobre: a permanente incerteza, fluidez e metamorfose que envolve a construção das identidades; a necessidade imprescindível de analisar as intersecções que transpassam as identidades; e a emergência de evitar que sujeitos "parecidos" sejam interpretados como "iguais", já que a experiência vivida entre os sujeitos é significativamente diferente. Essa compreensão torna o termo uma ferramenta pertinente na potencialização do currículo cultural de Educação Física, pois evita congelar e homogeneizar identidades e opõe-se a qualquer forma estática (que não percebe as hibridações), estanque (limitada em um único marcador identitário) e/ ou aditiva (número de identidades base representando o número de opressão) de analisar as relações de poder de ordem identitárias (SULLIVAN, 2003).

A fundamentação teórica que dá consistência ao termo tem como base os princípios dateoriaqueer, quenão destróinemabandonaousodecategoriasidentitárias, mas busca desestabilizá-las, mantendo essas categorias permanentemente abertas e seus significados contestáveis. A opção pela teoria queer justifica-se por ser uma abordagem construcionista social que desafia os entendimentos essencialistas e universalistas de identidade, enfatizando qualquer forma de identidade, como um princípio organizador, político e social (SEIDMAN, 1996).

Corroborando a ideia de identidade como um erro necessário (BUTLER, 1993), almejamos que a instabilidade conceitual provocada pelo uso do termo 'TRANSidentidade' possa consolidar nos docentes que atuem com o currículo cultural de Educação Física a visão de identidade num sentido plural, híbrido, performático, fluido, político, aberto, processual e instável.

Em resumo, o que estamos sugerindo é a mudança na nomenclatura de currículo, de um "documento de identidade"” (SILVA, 2007) para um "documento de TRANSidentidade", entendendo que essa alteração elucida e ratifica: a importância de se construir um currículo aberto, que acolhe todas as identidades e não apenas 
escolhe e/ou prioriza as identidades que são prejulgadas socialmente como inferiores e a importância de investigar e problematizar as singularidades identitárias formadas dentro das próprias diferenças; ações fundamentais que sustentam o caráter de improbabilidade identitária que se quer formar do currículo pós-crítico (NEIRA, 2009, p. 139).

\section{4 ‘TRANSIDENTIDADE’: UMA PEDAGOGIA VEROSSÍMIL}

Para se atender às exigências educacionais do mundo moderno, influenciado pelas profundas transformações políticas, sociais e culturais que impactam nas "formas de ser" dos indivíduos e das instituições, a Educação e a Educação Física precisam, prioritariamente, levar em consideração as novas identidades múltiplas e localizadas que estão surgindo. Assim, será possível consumar um projeto de currículo acolhedor, inclusivo e crítico.

Nessa perspectiva curricular, a inclusão de todos na sociedade e na escola só se cumpre a partir do acolhimento da narrativa das várias histórias de vida das múltiplas identidades. Para tanto, é necessário ouvir mais os indivíduos envolvidos no processo educativo; rompendo com o silêncio sepulcral de identidades que são tachadas como inferiores e de identidades não tidas como prioridades pelos currículos (identidades construídas no interior dos marcadores identitários). É importante frisar que estamos tratando de identidades em construção e desconstrução contínua. Intervir apenas em grupos identitários considerados marginalizados, rejeitados e/ ou oprimidos acaba forjando uma pedagogia que advoga um tratamento diferencial limitado às identidades socialmente definidas. Esse tipo de condução didática reforça o binarismo "vítima" versus "opressores", (pobre versus rico, branco versus negro, homem versus mulher, homossexual versus heterossexual), e não considera o caráter complexo, múltiplo, atravessado e contraditório das identidades, ou seja, não inclui toda identidade.

Não estamos questionando a importância de uma já consagrada práxis pedagógica pós-crítica e os avanços que ela trouxe para a Educação Física. Nosso adendo incide na emergência de se concretizar uma pedagogia pós-crítica que se comprometa com a "TRANSidentidade" e conduza o docente a produzir um processo ensino-aprendizagem focado não só na diversidade identitária, mas também nos processos discursivos pelos quais as identidades são formadas, em suas múltiplas camadas (CANEN, 2020).

Advertimos que, na prática, tal recomendação põe em foco barreiras políticas, pedagógicas e comportamentais que são condescendentes com os dispositivos sociais de normalização identitária e incentivadoras de ações educativas sustentadas sobre uma concepção essencialista de identidade (HALL, 2008; WOODWARD, 2014).

Aprimeira éa atual conjuntura política (ultradireita, neoliberal, ultraconservadora e protofascista). Essa forma de governar, através de formas explícitas, tais como projeto de lei 867/2015 (escola sem partido), projeto de lei 13.415/2017 (reforma do ensino médio), Emenda Constitucional 95/2016 (limita gastos em educação), aprovação da "autoritária" Base Nacional Comum Curricular (BNCC), censura nas 
escolas, tem interferido diretamente no processo ensino-aprendizagem, sobretudo pela disseminação de ideologias que tentam restringir temas que problematizem questões morais, sociais, culturais, políticas, religiosas, comportamentais e sexuais que estejam em desacordo com a identidade ideologicamente projetada; coagindo à predisposição de docentes e discentes que entendem a necessidade de refletir e dialogar sobre as novas identidades em construção (ALVES et al., 2021).

A segunda está ligada à falta de incentivo à formação continuada de professores. Mesmo regulamentada por diversos documentos oficiais, (LDB 9394/96, Plano Nacional de Educação - PNE (2014-2024), Resolução CNE/CEB 04/2010, que define as Diretrizes Curriculares Nacionais Gerais para Educação Básica), percebese pouco investimento e incentivo por parte das esferas educacionais (NOGUEIRA; BORGES, 2021). Quando não existe motivação pessoal por parte do docente com relação às questões próprias da contemporaneidade (avanço científico e tecnológico, globalização, multiculturalismo, intolerância, preconceito, identidade, dentre outras), fica evidente a dificuldade de intervir no enfrentamento pacificador desses tipos de conflitos. Como resultado, vemos respostas/soluções sem nexo ou inconsistentes que, por vezes, podem ser significativamente ainda mais prejudiciais ao processo educacional que se quer atento às identidades fluidas, provisórias, inacabadas, performáticas e/ou híbridas.

Aterceiraéaprópriaatmosferarelacional construídaemtempos de "modernidade líquida", identificada como efêmera, niilista, vazia de sentimentos, valores e sentidos. Essa fragilidade de laço entre pessoas, representada na superficialidade de se relacionar com o outro (BAUMAN, 2001), tem tornado a sociedade cada vez mais indiferente com as necessidades e problemas alheios. A escola, mesmo influenciada por esse contexto social desprovido de valores fundamentais ao convívio, precisa se transformar num espaço acolhedor que problematize a naturalização de perfis identitários marcados como ideais; indispensável para afastar de vez o preconceito e promover o respeito às diferenças.

Mediante o exposto, é inegável que, apesar do esforço docente, grupos conservadores tentam rebater tudo que consideram como "ameaça", na medida em que essas identidades de oposição acenam para o movimento constante (WEEKS, 2010, p. 35). A única possibilidade de ser resistência nesse contexto adverso é capacitando o docente com os referenciais pós-modernos; teorias que, quando aprofundadas, são capazes de fomentar reflexões e intervenções oportunas no trato com as identidades que estão em permanente estado de construção, desconstrução e reconstrução. Essa lacuna precisa ser rapidamente preenchida para que discursos pretensamente homogeneizadores que estereotipam, calam e interditam identidades não se sobreponham aos diálogos críticos e conscientizadores que percebem a identidade como um local não fixo de lutas, engajamentos e contestações (JAGOSE, 1997).

Por mais que já esteja sendo colocada em prática uma pedagogia pós-crítica que questiona preconceitos e trabalha em prol de uma sociedade mais justa e menos discriminatória, que reflete sobre as relações desiguais de poder entre as diversas culturas, que desestabiliza o regime que invisibiliza conhecimentos produzidos fora 
do escopo da cultura ocidental, que abre espaço para outras vozes e manifestações culturais, atribuindo um olhar mais plural para a edificação de propostas que preservem o respeito à existência do "outro", parte desse fazer docente continua alimentando uma falsa democratização do ensino, ao valorizar a pluralidade identitária e não refletir a identidade num sentido subjetivo e hibrido. Essa miopia tem provocado a construção de práticas pedagógicas limitadas ao diálogo e reconhecimento de algum "marcador mestre" (CANEN; GRANT, 2001), o que acaba ignorando a fluidez e intersecções presentes em identidades individuais; fortalecendo o congelamento das identidades e diferenças; reduzindo a esfera do conhecimento cultural ao simples reconhecimento de que existem culturas diferentes coabitando um mesmo espaço. Por consequência, esfalfando pedagogicamente ações concretas que poderiam efetivar uma melhor condição de equidade nos espaços de aula de Educação Física.

À vista disso, sugere-se que o caminho pedagógico a ser desenhado subverta padrões excludentes que aprisionam indivíduos em identidades produzidas e legitimadas pelo discurso eurocêntrico, racializado e, principalmente, universalizante. O problema não é o uso de termos que denominam ou expressam determinadas categorias identitárias, mas o uso indiscriminado desses termos como se representassem categorias universais, essenciais, a-históricas, apolíticas e estáveis, não se trazendo para o debate as exclusões que tais categorias produzem (BUTLER, 1993).

Embora exista uma sinalização para que o diálogo com outros campos de conhecimento ampliem e enriqueçam as análises pós-críticas do fenômeno educativo, esse nos parece um território ainda pouco explorado e de difícil trânsito entre os docentes curriculistas de Educação Física, que continuam, em sua maioria, apoiando suas reflexões na intersecção entre dois campos teóricos principais: os estudos culturais e o multiculturalismo crítico. Se apropriar de toda essa vastidão espacial de conhecimentos, aglutinada na expressão "teorias pós-críticas", exige tempo, envolvimento e dedicação do docente, principalmente por não se constituir num conjunto de doutrinas comuns, de modo que, por vezes, até mesmo se opõem (BORGES, 2019).

Fazendo uma breve incursão por algumas das várias teorias pós-críticas, identificamos que o conceito de identidade ganha contornos e definições variadas. No pós-modernismo, a identidade é descentrada, múltipla e fragmentada (NEIRA, 2009, p. 165). No pós-estruturalismo, a identidade é indeterminada e instável, chegando, inclusive, na afirmação de que "não existe identidade, tudo é diferença" (NEIRA, 2009, p. 179-180). No pós-colonialismo, as identidades são complexas e multifacetadas (SHOHAT; STAM, 2006). Nos estudos culturais, a identidade é relacional, simbólica e social (WOODWARD, 2014); binária e bipartida (BHABHA, 1998); cultural (HALL, 2004, 2008). No multiculturalismo crítico, a identidade é aberta, híbrida, plural, dinâmica e de fronteira (CANDAU, 2008, 2013). No entanto, mesmo com toda essa profusão de sentidos, é possível constatar entrecruzamentos epistemológicos e pontos de apego em comum, que pressupõem ações educativas que se destinam à formação de identidades múltiplas (BORGES, 2019).

Inspirados pelos estudos queer e na interseccionalidade, buscamos expandir o potencial de contestação identitária na prática docente pedagogicamente pós-crítica 
e culturalmente orientada. Nossa pretensão é provocar o docente a reconhecer, no dia a dia da Educação Física, a identidade como um estado de transição permanente; como uma totalidade singular, atravessada simultaneamente por diversos contextos, culturas, políticas e relações de poder; e, com isso, evitar que o encaminhamento das ações docentes a favor das identidades marginalizadas se transforme em novos essencialismos identitários. Esse olhar pedagógico faz com que o docente compreenda que reduzir o trabalho da Educação Física cultural ao diálogo com os marcadores identitários, mesmo que o objetivo seja conferir sentimento de pertença a grupos coletivos específicos e garantir-lhes seus direitos à representação nos espaços sociais e culturais, impede a mobilidade e hibridação intrínseca às identidades individuais (CANEN, 2020) e termina por construir "guetizações" e "universalizar particularismos" (BOURDIEU, 2005, p. 148).

Para tornar essa realidade possível é preciso homologar a imiscuidade entre pedagogia e "TRANSidentidade", que destaca a escola como um espaço coabitado por seres de possibilidades, não cabendo aos docentes restringir, limitar ou mesmo destruir tais possibilidades. Acreditamos que esse caráter inconcluso, atribuído pela interpretação da identidade como seres de possibilidades, conduzirá o docente curriculista a revisitar, constantemente, seu plano de curso, plano de ensino e plano de aula a fim de identificar se as identidades discentes que compõem o seu microcampo de intervenção/ação estão sendo contempladas.

Santos (2016) buscou analisar junto a um grupo de professores como as ações didáticas de tematização e problematização vão sendo tecidas no currículo cultural da Educação Física, bem como suas possibilidades de potencialização para novas tessituras. As análises observaram que partes das ações didáticas fizeram ver que, por vezes, as problematizações encerram-se nas inversões hierárquicas, o que pode levar a tematização ao risco do restabelecimento de novos pares binários, hierarquizados por outros marcadores identitários presentes nas práticas corporais, como, por exemplo, na oposição entre idosos habilidosos e idosos inábeis na prática do skate. Além disso, chamou a atenção para o fato de que, em alguns momentos, os professores observados apartaram o vetor-problematização dos acontecimentos referentes às manifestações tematizadas, deixando a problematização na esfera dos aspectos macrossociais que envolvem a discriminação e os preconceitos étnicos.

A importância do corolário ora exposto fundamenta nossa defesa em prol de uma proposta pedagógica que trabalhe os aspectos macrossociais (marcadores identitários) em sinergia com os aspectos microssociais (subjetividades). Esse enfoque, facilitado pelo uso do termo TRANSidentidade, torna o docente proficiente dos caminhos metodológicos necessários à desconstrução da lógica naturalizante e essencialista que congelam as identidades e que permitem que as diferenças no interior das próprias diferenças sejam identificadas e problematizadas.

A escola e a Educação Física, através do seu currículo, precisam oferecer aos discentes um espaço de aprendizagem baseado no acolhimento, na hospitalidade, no reconhecimento da outridade (LÉVINAS, 1999), ou seja, extinguindo qualquer tentativa de emparelhamento das identidades, que suprime as diferenças dos sujeitos que se relacionam. O princípio da alteridade é condição basilar para tornar 
factíveis estratégias pedagógicas mais humanas e compromissadas com o "outro" que precisam ser percebidos e ouvidos para serem compreendidos e conhecidos; e, só assim, atraídos e incluídos pelos espaços educativos.

Se as identidades que os alunos podem construir no espaço escolar são provisórias, descartáveis, rejeitadas e abandonadas (LOURO, 1999), é inadmissível que os planejamentos do ensino (plano de ensino, plano de curso e plano de aula) sejam baseados e sistematizados num modelo aditivo de identidade, que afirma a identidade como uma soma de identidades-base que existem simplesmente independentes, lado a lado, umas das outras (SULLIVAN, 2003); ora "futebol e gênero", ora "futebol e etnia", ora "futebol e classe social", ora "futebol e culturas". Ignorar a existência de relações de poder imbricadas nas identidades é uma estratégia equivocada, que acaba comprometendo a qualidade das práticas pedagógicas em sua condição pós-críticas.

Se o que se pretende é formar cidadãos para uma sociedade menos desigual, como não debater as relações de gênero e classe que envolvem os esportes? Ou as questões de religião e etnia presentes na capoeira? Como não problematizar a aluna adolescente, negra, homossexual e pobre que gosta de jogar futebol e sofre preconceito da turma? Ou o aluno adolescente, branco, heterossexual, classe alta que não gosta de jogar futebol e sofre preconceito dos amigos brancos, heterossexuais, classe alta, que amam jogar futebol? Os dados da pesquisa realizada por Corsino (2015) confirmam que é possível perceber múltiplas formas de discriminação entre os alunos durante as aulas. A Educação Física não pode negar a existência dessa multiplicidade de opressão que opera de forma interseccionalizada; ou mesmo limitar a discussão a rodas de conversas que demonstram ser insuficientes na eliminação dessas hierarquizações (CORSINO, 2015). É preciso ir além, encarar que todo discente é uma identidade em transição com vivências particulares, ou seja, uma "TRANSidentidade".

Concluímos que a "TRANSidentidade", ao incentivar a coalizão entre várias teorias pós-críticas (estudos culturais, multiculturalismo crítico, teoria queer e interseccionalidade), assegura o sabor de novidade e a verve revolucionária fundamental para resolução de problemas identitários e projetos curriculares que buscam suplantar qualquer tipo de "ficção naturalizante das identidades apenas como meio para a obtenção de direitos" (MISKOLCI, 2011, p. 49).

\section{REFERÊNCIAS}

ALTMANN, Helena. Educação física escolar: relações de gênero em jogo. São Paulo: Cortez, 2015.

ALVES, Antônio Souza et al. As determinações do Ultraliberalismo e Neoconservadorismo para as políticas públicas de educação no contexto atual de retrocessos e ataques à Democracia. Brazilian Journal of Development, v. 7, n. 7, p. 72423-72436, jul. 2021. Disponível em: https://www.brazilianjournals.com/index.php/BRJD/article/view/33160/pdf. Acesso em: 11 set. 2021. DOI: https://doi.org/10.34117/bjdv7n7-427 
ARAÚJO, Bárbara Gicélia da Silva et al. Participação de adolescentes brasileiros nas aulas de Educação Física: revisão sistemática. Pensar a Prática, v. 22, n. 53618, p. 1-11, set. 2019. Disponível em: https://www.revistas.ufg.br/fef/article/view/53618/33754. Acesso em: 3 mar. 2019. DOI: https://doi.org/10.5216/rpp.v22.53618.

BAUMAN, Zygmunt. Bauman e a Educação. Belo Horizonte: Autêntica, 2009a.

BAUMAN, Zygmunt. Confiança e medo na cidade. Rio de Janeiro: Jorge Zahar, 2009b.

BAUMAN, Zygmunt. Modernidade líquida. Rio de janeiro: Jorge Zahar, 2001.

BHABHA, Homi. O local da cultura. In: HOLLANDA, Heloísa B. Pós-modernismo e política (org.). Belo Horizonte: Rocco, 1998. Disponível em: https://repositorio.ufsc.br/xmlui/bitstream/ handle/123456789/1387/bhabha1.pdf? sequence=1\&isAllowed=y. Acesso em: 19 mar. 2020.

BORGES, Clayton Cesar de Oliveira. Governo, verdade, subjetividade: uma análise do currículo cultural da Educação Física. 2019. 181 f. Tese (Doutorado em Educação) Universidade de São Paulo, Faculdade de Educação, São Paulo, 2019. Disponível em: http://www.gpef.fe.usp.br/teses/borges_02.pdf. Acesso em: 14 nov. 2020.

BOURDIEU, Pierre. A dominação masculina. 4. ed. Rio de Janeiro: Bertrand Brasil, 2005.

BRAH, Avtar. Diferença, diversidade, diferenciação. Caderno Pagu, v. 26, p. 329-376, 2006. Disponível em: https://www.scielo.br/j/cpa/al B33FqnvYyTPDGwK8SxCPmhy/?lang=pt\&format=pdf. Acesso em: 9 jul. 2020.

BRASIL. [Constituição (1988)]. Constituição da República Federativa do Brasil. Brasília, DF: Senado Federal, 2016. Disponível em: https://www2.senado.leg.br/bdsf/bitstream/ handle/id/518231/CF88_Livro_EC91_2016.pdf. Acesso em: 5 mar. 2019.

BRASIL. Lei no 9394, 20 de dezembro de 1996. Estabelece as diretrizes e bases da educação nacional. Diário Oficial [da] República Federativa do Brasil, Brasília, n. 248, p. 27833, 23 dez. 1996. Seção 1. Disponível em: http://portal.mec.gov.br/arquivos/pdf/lei\%20 9394.pdf. Acesso em: 5 mar. 2019.

BUTLER, Judith. Problemas de gênero. Feminismo e subversão de identidade. Rio de Janeiro: Civilização Brasileira, 2010.

BUTLER, Judith. Critically queer. GLQ: A Journal of Lesbian and Gay Studies, v. 1, n. 1, p. 17-32, Nov. 1993. Disponível em: https://www.deepdyve.com//p/duke-university-press/ critically-queer-G1ejsI2qQS. Acesso em: 3 out. 2020. DOI: https://doi.org/10.1215/10642684$\underline{1-1-17}$

CANDAU, Vera Maria Ferrão. Direitos humanos, educação e interculturalidade: as tensões entre igualdade e diferença. Revista Brasileira de Educação, v. 13, n. 37, p. 45-56, jan./ abr. 2008. Disponível em: https://www.scielo.br/j/rbedu/a/5szsvwMvGSVPkGnWc67BjtC/?lan $\mathrm{g}=$ pt\&format=pdf. Acesso em: 7 mar. 2019.

CANDAU, Vera Maria Ferrão. Multiculturalismo e educação: desafios para a prática pedagógica. In: MOREIRA, Antônio Flávio Barbosa; CANDAU, Vera Maria Ferrão. (orgs.). Multiculturalismo: Diferenças Culturais e Práticas Pedagógicas. 10. ed. Petrópolis: Vozes, 2013. p. 38-66.

CANEN, Ana. Currículo e multiculturalismo: reflexões a partir de pesquisas realizadas. In: SANTOS, Lucíola Licínio de Castro Paixão; FAVACHO, André Márcio Picanço. (orgs.). Políticas e práticas curriculares: desafios contemporâneos. Curitiba: Editora CRV, 2012. p. 237-249. 
CANEN, Ana. O multiculturalismo e seus dilemas: implicações na educação. Dossiê Educação e Desenvolvimento. Comunicação e política, v. 25, n. 2, p. 91 - 107, 2020.

CANEN, Alberto; CANEN, Ana. Organizações multiculturais. Rio de Janeiro: Ciência Moderna, 2005.

CANEN, Ana; GRANT, Nigel. "Conhecimento e Multiculturalismo em Políticas Educacionais no Mercosul: limites e possibilidades". In: CANEN, Ana; MOREIRA, Antônio Flávio Barbosa (org.). Ênfases e omissões no currículo. São Paulo: Papirus, 2001. p. 163-194.

CERVO, Amado Luiz; BERVIAN, Pedro Alcino; SILVA, Roberto da. Metodologia científica. 6. ed. São Paulo: Pearson Prentice Hall, 2007.

COHEN, Cathy. Punks, bulldaggers, and welfare queens: the radical potential of queer politics? GLQ: A Journal of Lesbian and Gay Studies, v. 3, n. 4, p. 437-465, 1997. Disponível em: http://www.985queer.queergeektheory.org/wp-content/uploads/2013/04/ Cohen-Punks-Bulldaggers-and-Welfare-Queens.pdf. Acesso em: 10 set. 2020.

COLLING, Leandro. A igualdade não faz o meu gênero: em defesa das políticas das diferenças para o respeito à diversidade sexual e de gênero no Brasil 1. Contemporânea: Revista de Sociologia da UFSCar, v. 3, n. 2, p. 405-405, 2013. Disponível em: https://www. contemporanea.ufscar.br/index.php/contemporanea/article/view/149. Acesso em: 8 out. 2020.

CORSINO, Luciano Nascimento. Raça, gênero e a lei 10.639/03 no âmbito da educação física escolar: percepções docentes. Revista Artes de Educar, v. 1, n. 2, p. 247-262, 2015. Disponível em: https://www.e-publicacoes.uerj.br/index.php/riae/article/view/14187/13416. Acesso em: 12 out. 2020.

CRENSHAW, Kimberlé. Mapping the margins: intersectionality, identity politics, and violence against women of color. Stanford Law Review, v. 43, n. 6, p. 1241-1299, 1991. Disponível em: Mapeando as Margens: Interseccionalidade, Política de Identidade e Violência contra Mulheres de Cor no JSTOR. Acesso em: 5 out. 2020. DOI: https://doi.org/10.2307/1229039

DAYRELL, Juarez. A escola como espaço sócio-cultural. In: DAYRELL, Juarez. (org.). Múltiplos olhares sobre educação e cultura. Belo Horizonte: UFMG, 1996. p. 136-178.

DEVIDE, Fabiano Pires. (org.). Estudos de gênero na educação física e no esporte. Curitiba: Appris, 2017.

DORNELLES, Priscila Gomes; WENETZ, Ileana; SCHWENGBER, Maria Simone Vione. (orgs.). Educação física e gênero: desafios educacionais. ljuí: Unijuí, 2014.

DORNELLES, Priscila Gomes; WENETZ, Ileana; SCHWENGBER, Maria Simone Vione. (orgs.). Educação física e sexualidade: desafios educacionais, ljuí: Unijuí, v. 1, p. 23-49, 2017.

ELIAS, Claudia de Souza Rodrigues et al. When is the end? A narrative review on the termination of the school term for mentally disabled students. SMAD, Revista Eletrônica Saúde Mental Álcool Drog. (Ed. port.). v. 8, n. 1, jan.-abr. 2012. Disponível em: http:// pepsic.bvsalud.org/pdf/smad/v8n1/en_08.pdf. Acesso em: 15 abr. 2020.

FOUCAULT, Michel. Microfísica do poder. 24. ed. São Paulo: Graal, 2012.

GALLO, Sílvio Donizetti de Oliveira. Diferenças, multiplicidade, transversalidade: para além da lógica identitária da diversidade. In: RODRIGUES, Alexsandro; DALLAPICULA, Catarina; FERREIRA, Sérgio Rodrigo da Silva. Transposições: lugares e fronteiras em sexualidade e educação. Vitória: EDUFES, 2015. p.187-202. 
GALVE, José Luiz; TRALLERO, Manuel; HEREDERO, Eladio. Las adaptaciones curriculares individuales (ACl). Madrid: CEPE, 2002.

HALL, Stuart. A identidade cultural na pós-modernidade. 9. ed. Rio de Janeiro: DP\&A, 2004.

HALL, Stuart. Quem precisa da identidade? In: SILVA, Tomaz Tadeu da. (org.). Identidade e diferença: a perspectiva dos Estudos Culturais. Petrópolis: Vozes, 2008. Disponível em: https://www.academia.edu/39471416/Identidade e Diferen\%C3\%A7a A perspectiva dos Estudos_Culturais_Tomaz_Tadeu_da_Silva. Acesso em: 17 mar. 2020.

IBGE - INSTITUTO BRASILEIRO DE GEOGRAFIA E ESTATÍSTICA. Pesquisa Nacional por Amostra de Domicílios Contínua (PNAD) 2019: Módulo Educação. Rio de Janeiro: IBGE, 2019. Disponível em: https://biblioteca.ibge.gov.br/visualizacao/livros/liv101657 informativo.pdf. Acesso em: 02 abr. 2019. O COPYRIGHT É DE 2019(ISBN), A PESQUISA FOI FEITA NO ANO ANTERIOR

JAGOSE, Annamarie Rogowski. Queer theory: an introduction. New York: New York University, 1997.

KINCHELOE, Joe Lyons; STEINBERG, Shirley. Repensar el multiculturalismo. Barcelona: Octaedro, 1999.

KNUDSEN, Susanne. Intersectionality: a theoretical inspiration in the analysis of minority cultures and identities in textbooks. In: BRUILLARD, Éric; et al. (ed.). Caught in the Web or Lost in the Textbook? Caen: IARTEM, 2006. p. 61-76. Disponível em: https://repository.gei. de/bitstream/handle/11428/25/818102888 2015 A.pdf? sequence=1\&isAllowed=y. Acesso em: 3 jul. 2020.

LACLAU, Ernesto. Emancipación y diferencia. Buenos Aires: Ariel, 1996

LÉVINAS, Emmanuel. Alterity and transcendence. London: The Athlone, 1999.

LOURO, Guacira Lopes (org.). O corpo educado: pedagogias da sexualidade. Belo Horizonte: Autêntica, 1999. Disponível em: https://core.ac.uk/download/pdf/30353576.pdf Acesso em: 13 ago. 2020.

MALDONADO, Daniel Teixeira et al. Indícios de mudanças na prática pedagógica dos professores de educação física escolar: análise dos estudos publicados em anais de eventos nacionais. Corpoconsciência, v. 22, n. 1, p. 77-92, jan./abr., 2018. Disponível em: https://periodicoscientificos.ufmt.br/ojs/index.php/corpoconsciencia/article/view/6279. Acesso em: 3 out. 2020.

MCDONALD, James. Coming out in the field: a queer reflexive account of shifting researcher identity. Management Learning, v. 44, n. 2, p. 127-143, 2013. Disponível em: https:// journals.sagepub.com/doi/abs/10.1177/1350507612473711 . Acesso em: 30 jun. 2020. DOI: https://doi.org/10.1177/1350507612473711

MISKOLCI, Richard. Não somos, queremos: notas sobre o declínio do essencialismo estratégico. In: COLLING, Leandro (Org.). Stonewall 40 + o que no Brasil? Salvador, Edufba, 2011. p. 37-56.

MISKOLCl, Richard. Batalhas morais: política identitária na esfera pública técnicomidiatizadora. Belo Horizonte: Autêntica, 2021.

NEIRA, Marcos Garcia. Educação Física, currículo e cultura. São Paulo: Phorte, 2009. 
NEIRA, Marcos Garcia. O currículo cultural e a afirmação das diferenças. In: BOTO, Carlota et al. (org). A escola pública em crise: inflexões, apagamentos e desafios. São Paulo: FEUSP, 2020. p. $183-202$.

NEIRA, Marcos Garcia; SANTOS, Ivan Luis. A reterritorialização do pensamento freiriano no currículo cultural da educação física. In: SOUZA, C. A; NOGUEIRA, V. A; MALDONADO, D. T. (orgs.). Educação Física Escolar e Paulo Freire: ações e reflexões em tempos de chumbo. São Paulo: Editora CRV, 2019. v. 38, cap. 3, p. 51-66.

NEVES, Marcos Ribeiro das. O currículo cultural de Educação Física em ação: efeitos nas representações culturais dos estudantes sobre as práticas corporais e seus representantes. Dissertação (Mestrado em Educação e Ciências Sociais: Desigualdades e Diferenças) - Faculdade de Educação, Universidade de São Paulo, São Paulo, 2018. Disponível em: MARCOS RIBEIRO DAS NEVES.pdf (usp.br) Acesso em: 29 set. 2020.

NOGUEIRA, Adrinelly Lemes; BORGES, Maria Célia. O PNE (2014-2024) e as políticas para a formação continuada de professores. Cadernos da FUCAMP, v. 20, n. 43, p. $13-$ 32, 2021. Disponível em: http://fucamp.edu.br/editora/index.php/cadernos/article/view/2315. Acesso em: 06 set. 2021.

NUNES, Mário Luiz Ferrari; RUBIO, Kátia. O(s) currículo(s) da Educação Física e a constituição da identidade de seus sujeitos. Currículo sem Fronteiras, v. 8, n. 2, p. 55-77, jul./dez. 2008. Disponível em: http://www.curriculosemfronteiras.org/vol8iss2articles/nunesrubio.pdf. Acesso em: 17 mar. 2019.

OLIVEIRA, Rogério Cruz de; DAOLIO, Jocimar. Educação Física, cultura e escola: da diferença como desigualdade à alteridade como possibilidade. Movimento (Porto Alegre), v. 16, n. 1, p. 149-167, 2010. Disponível em: https://www.seer.ufrgs.br/Movimento/article/ view/8279. Acesso em: 9 set. 2019. DOI: https://doi.org/10.22456/1982-8918.8279

OLIVEIRA, Silvio Luiz. Tratado de metodologia científica. São Paulo: Pioneira, 1997.

OLIVEIRA JUNIOR, Jorge Luiz de. Significações sobre o currículo cultural da Educação Física: cenas de uma escola municipal paulistana. Dissertação (Mestrado em Educação) - Faculdade de Educação, Universidade de São Paulo, São Paulo, 2017. Disponível em: JORGE_LUIZ_DE_OLIVEIRA_JUNIOR.pdf (usp.br) Acesso em: 21 jun. 2019.

SANTOS, Ivan Luis dos. A tematização e a problematização no currículo cultural da Educação Física. 2016. 299 f. Tese (Doutorado) - Faculdade de Educação, Universidade de São Paulo, São Paulo, 2016. Disponível em: http://www.gpef.fe.usp.br/teses/ivan_01.pdf. Acesso em: 19 mar. 2020.

SEIDMAN, Steven. Queer theory/sociology. Cambridge/Oxford: Blackwell, 1996.

SHOHAT, Ella; STAM, Robert. Crítica da imagem eurocêntrica: multiculturalismo e representação. São Paulo: Cosac Naify, 2006.

SILVA, Tomaz Tadeu da. Documentos de identidade: uma introdução às teorias do currículo. 2. ed. Belo Horizonte: Autêntica, 2007.

SOUZA SANTOS, Boaventura de. "Dilemas do nosso tempo: globalização, multiculturalismo e conhecimento". Educação e Realidade, v. 26, n. 1, p. 13 - 32, 2001. Disponível em: https://seer.ufrgs.br/educacaoerealidade/article/view/41311/26143. Acesso em: 18 jul. 2020.

SULLIVAN, Nikki. A critical introduction to queer theory. New York: New York University, 2003. 
TORRES-SANTOMÉ, Jurjo. Globalização e interdisciplinaridade: o currículo integrado. Porto Alegre: Artes Médicas, 1998.

VASCONCELOS, Fatima Ferreira; CAMPOS, Pedro Humberto Faria. Ancoragem da representação social da Educação Física escolar nas abordagens teóricas da Educação Física. Motrivivência, v. 26, n. 43, p. 164 -182, 2014. Disponível em: https://periodicos.ufsc. br/index.php/motrivivencia/article/view/2175-8042.2014v26n43p164/28117. Acesso em: 18 Jul 2019.

VIEIRA, Rubens Antonio Gurgel. Conceitos em torno de uma Educação Física menor: potencialidades do currículo cultural para esquizoaprender como política cognitiva. 245f. Tese (Doutorado). Universidade Estadual de Campinas (UNICAMP). Faculdade de Educação. 2020. Disponível em: https://www.unicamp.br/unicamp/teses/2020/02/05/ conceitos-em-torno-de-uma-educacao-fisica-menor-potencialidades-do-curriculo. Acesso em: 18 out. 2020 .

WEEKS, Jeffrey. O corpo e a sexualidade. In: LOURO, Guacira Lopes (org.). O corpo educado: pedagogias da sexualidade. 3. ed. Belo Horizonte: Autêntica, 2010. p. 35-38. Disponível em: https://core.ac.uk/download/pdf/30353576.pdf. Acesso em: 21 out. 2020.

WOODWARD, Kathryn. Identidade e diferença: uma introdução teórica. In: SILVA, Tomaz Tadeu da (org.). Identidade e diferença: a perspectiva dos Estudos Culturais. 14. ed. Petrópolis,RJ: Vozes, 2014. p. 73 -102. 
Abstract: The aim of this study is to discuss the process of exclusion resulting from curricular projects based on ready-made minority identities, in order to question the the naturalized majoritarian social representations in Physical Education. A qualitative bibliographic review technique was used, constituting a narrative review. The Google Scholar database was consulted, in the period between 2000 and 2021, using a Boolean indicator and descriptors in quotation marks. This study is justified by the fact that several didactic-pedagogical paths present in the literature disregard different subjectivities, experiences and differences existing within the differences, neglecting the construction of identities formed within the identity markers themselves. It is concluded that, by encouraging the coalition between various postcritical theories, it ensures the flavor of novelty and the fundamental revolutionary verve for solving identity problems and curriculum projects that seek to supplant any type of naturalizing fiction.

Keywords: Physical Education. Intersectionality. Sexual and gender minorities. Social construction of gender.

Resumen: El objetivo de este estudio es discutir el proceso de exclusión resultante de proyectos curriculares basados en identidades minoritarias prefabricadas, con el fin de cuestionar las representaciones sociales mayoritarias naturalizadas en la Educación Física. Se utilizó la técnica de revisión bibliográfica cualitativa, constituyéndose como una revisión narrativa. Se consultó la base de datos de Google Académico, en el período 2000-2021, utilizando un indicador booleano y descriptores entre comillas. Este estudio se justifica por el hecho de que varios caminos didáctico-pedagógicos presentes en la literatura no consideran diversas subjetividades, experiencias y diferencias existentes dentro de las diferencias, descuidando la construcción de identidades formadas dentro de los propios marcadores identitarios. Se concluye que al fomentar la coalición entre varias teorías poscríticas, se asegura el sabor de novedad y el brío revolucionario fundamental para la resolución de problemas identitarios y proyectos curriculares que buscan suplantar cualquier tipo de ficción naturalizadora.

Palabras clave: Educación Física. Interseccionalidad. Minorías sexuales y de género. Construcción social del género. 


\section{LICENÇA DE USO}

Este é um artigo publicado em acesso aberto (Open Access) sob a licença Creative Commons Atribuição 4.0 Internacional (CC BY 4.0), que permite uso, distribuição e reprodução em qualquer meio, desde que o trabalho original seja corretamente citado. Mais informações em: https://creativecommons.org/licenses/by/4.0

\section{CONFLITO DE INTERESSES}

Os autores declararam que não existe nenhum conflito de interesses neste trabalho.

\section{CONTRIBUIÇÕES AUTORAIS}

Carlos Henrique Rego Gonçalves: Concepção, coleta de dados, elaboração escrita original, análise de dados.

Carlos Alberto Figueiredo da Silva: Validação, formatação, metodologia, supervisão, revisão final do texto.

\section{FINANCIAMENTO}

O presente trabalho foi realizado com apoio da Universidade Salgado de Oliveira.

\section{ÉTICA DE PESQUISA}

O projeto de pesquisa foi encaminhado e aprovado pelo Comitê de Ética em Pesquisa da Universidade Salgado de Oliveira, número do parecer: 5.103.778, e CAAE: 47198421.0.0000.5289

\section{COMO REFERENCIAR}

GONÇALVES, Carlos Henrique Rego; SILVA., Carlos Alberto Figueiredo da. Transidentidades para uma educação física acolhedora. Movimento (Porto Alegre), v.27, p.e27077, jan./dez. 2021. Disponível em: https://seer.ufrgs.br/ Movimento/article/view/116297. Acesso em: [dia] [mês abreviado]. [ano]. DOI: https://doi.org/10.22456/1982-8918.116297

\section{RESPONSABILIDADE EDITORIAL}

Alex Branco Fraga*, Elisandro Schultz Wittizorecki*, Ivone Job*, Mauro Myskiw*, Raquel da Silveira*

*Universidade Federal do Rio Grande do Sul, Escola de Educação Física, Fisioterapia e Dança, Porto Alegre, RS, Brasil. 